\title{
Avaliação do Ciclo de Vida de diferentes envoltórias para habitações de interesse social em Florianópolis
}

\author{
Life cycle assessment of different envelopes for \\ affordable housing in Florianópolis, Brazil
}

\section{Leticia Dalpaz de Azevedo Matheus Soares Geraldi Enedir Ghisi}

\section{Resumo}

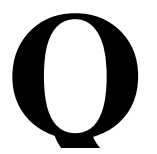

uando um componente construtivo é selecionado para melhorar o desempenho da edificação ao longo de sua operação, deve-se verificar o seu impacto ao longo de todo o ciclo de vida para assegurar a redução dos impactos ambientais. Dessa forma, o objetivo principal deste trabalho foi selecionar o conjunto de componentes construtivos com menor impacto ambiental para uso em habitações de interesse social em Florianópolis por meio da avaliação do ciclo de vida (ACV). Foi desenvolvida uma ACV utilizando dois tipos de parede e dois de cobertura. Para as paredes, considerou-se o uso de tijolo cerâmico com revestimento e tijolo de adobe com revestimento de argamassa de terra com cal. Para as coberturas foi considerada telha cerâmica com forro de madeira e telha cerâmica com laje maciça de concreto. O método de avaliação de impacto do ciclo de vida (AICV) utilizado foi o IMPACT 2002+. Os resultados obtidos foram comparados com a aplicação do método ReCiPe. Aplicou-se simulação computacional por meio do programa EnergyPlus para calcular o consumo energético anual. $\mathrm{O}$ conjunto que apresentou menor consumo energético foi o de parede de tijolo de adobe e cobertura com laje maciça. Os dois métodos utilizados para a fase de AICV apresentaram resultados coerentes para a maioria das categorias de impacto. Com isso, o conjunto de menor impacto ambiental obtido por meio da ACV foi o de parede de tijolo de adobe com cobertura com forro de madeira.

Palavras-chave: Avaliação do ciclo de vida. Simulação computacional de edificações. Habitação de interesse social.

${ }^{1}$ Leticia Dalpaz de Azevedo 1 Universidade Federal de Santa Catarina Florianópolis - SC -Brasil

${ }^{2}$ Matheus Soares Geraldi 2Universidade Federal de Santa Catarina Florianópolis - SC -Brasil

${ }^{3}$ Enedir Ghisi Universidade Federal de Santa Catarina Florianópolis - SC -Brasil

Recebido em 25/12/19 Aceito em 09/05/20

\begin{abstract}
When a construction component is selected to improve the performance of a building throughout its operation, its impact must be verified throughout the life cycle to ensure the reduction of environmental impacts. Hence, the main objective of this study was to select the set of construction components with the lowest environmental impact to use in affordable housing in Florianópolis, by means of life cycle assessment (LCA). An LCA was developed using two types of walls and two types of roofs. For the walls, ceramic bricks with coating and adobe bricks with lime earth mortar were considered. For the roofs, ceramic tiles with a wooden ceiling and ceramic tiles with a concrete slab were considered. The life cycle impact assessment (LCIA) method used was IMPACT 2002+. The results obtained were compared with the ReCiPe method. Computer simulation was applied through the EnergyPlus programme to calculate the annual energy consumption. The set with the lowest energy consumption was the adobe wall and concrete slab. Both methods used for the LCIA showed consistent results for most impact categories. Hence, the set with the lowest environmental impact obtained through the LCA was the adobe brick wall with a wooden ceiling.
\end{abstract}




\section{Introdução}

O setor da construção civil é um importante influenciador no consumo mundial de recursos naturais e energia elétrica, além de representar parcela significativa da economia no Brasil (ASADOLLAHFARDI; ASADI; KARIMI, 2015; BRASIL, 2017). Devido ao elevado consumo de recursos e à grande quantidade de melhorias que podem ser implementadas, este setor é o que apresenta o maior potencial e oportunidades na economia de energia e redução de emissão de carbono (KYLILI; ILIC; FOKAIDES, 2017).

Segundo a Agência Internacional de Energia (INTERNATIONAL..., 2019), é previsto o aumento da participação do consumo de energia elétrica nas edificações de $20 \%$ (2018) para 22\% em 2050. Esse aumento está relacionado principalmente aos sistemas de aquecimento ou resfriamento do ambiente, aquecimento de água e iluminação, que somam cerca de $70 \%$ da energia total consumida. Por meio de intervenções nesses sistemas e na envoltória da edificação é possível reduzir o consumo energético em até $50 \%$ (HARISH; KUMAR, 2016).

Além do consumo energético e de água, aspectos ecológicos, econômicos e sociais também influenciam na sustentabilidade de uma edificação. Entretanto, é comum não se considerar os custos dos impactos ambientais causados ao longo de um projeto. Considerar todas essas influências é essencial para que o setor da construção civil apresente desenvolvimento sustentável (BUYLE; BRAET; AUDENAERT, 2013).

Devido à maior conscientização dos impactos provocados pela operação das edificações, cresceu a busca pelo desenvolvimento de projetos que apresentem baixo consumo energético ao longo de seu uso (BUYLE; BRAET; AUDENAERT, 2013). Nesse contexto, a simulação computacional de edificações auxilia na tomada de decisões para a construção de ambientes que atendam os requisitos mínimos de desempenho com consumo reduzido de recursos. A simulação pode influenciar características de projeto, engenharia, operação e gerenciamento das edificações analisadas (WANG; ZHAI, 2016; HARISH; KUMAR, 2016).

A padronização das características consideradas e sua proximidade com a realidade é fundamental para a simulação. Essas informações têm sido cada vez mais fortalecidas pelo surgimento de normas e códigos que trazem requisitos de desempenho (WANG; ZHAI, 2016).

O método de avaliação do ciclo de vida (ACV) apresenta-se como uma ferramenta muito detalhada e completa para avaliação dos impactos provocados pelas edificações. A avaliação de todo o ciclo de vida de um empreendimento permite a identificação dos principais influenciadores dos potenciais impactos ambientais causados, facilitando a tomada de decisões para redução dos impactos ambientais. Sem essa visão global é possível que decisões sejam tomadas de forma a alterar somente o tipo de impacto que é causado, ou então apenas alterá-lo de lugar dentro do ciclo (ASADOLLAHFARDI; ASADI; KARIMI, 2015; CURRAN, 2013; RASHID; YUSOFF, 2015).

Conforme a NBR ISO 14040 (ABNT, 2014), um estudo de avaliação do ciclo de vida é composto por quatro fases: definição de objetivo e escopo, análise de inventário, avaliação de impactos e interpretação. Na primeira fase são definidos o nível de detalhamento e os limites da análise, que variam significativamente conforme o objetivo principal do estudo. A análise de inventário é a fase em que são levantados os dados conforme os limites definidos anteriormente. Na fase de avaliação de impactos, as informações obtidas na segunda fase são complementadas de forma a facilitar sua interpretação. Na última fase, os resultados são avaliados e as conclusões definidas, conforme o objetivo principal definido na primeira fase. Para alguns casos, é possível eliminar a fase de avaliação de impactos. Quando isso ocorre o estudo desenvolvido é denominado de inventário do ciclo de vida (ICV) e não mais de avaliação do ciclo de vida. É importante ressaltar que a técnica aplicada na ACV é iterativa, ou seja, cada fase apresentada necessita das informações obtidas em outras fases para garantir a veracidade das conclusões e medidas adotadas (ABNT, 2014).

Apesar de sua aplicação considerar todo o ciclo de vida do produto ou serviço, a ACV não tem como finalidade prever impactos ambientais de forma precisa ou absoluta, e sim estimar impactos potenciais, uma vez que sua metodologia depende da unidade de referência adotada (ABNT, 2014). Por causa de algumas de suas limitações, os resultados encontrados com a aplicação desse método devem ser interpretados e utilizados de forma criteriosa.

De acordo com a análise histórica desenvolvida por Buyle, Braet e Audenaert (2013), os primeiros estudos relacionados à ACV foram realizados entre os anos de 1960 e 1970. Com o envolvimento de instituições, foram desenvolvidos documentos e procedimentos para o uso da avaliação do ciclo de vida, atraindo e unindo profissionais interessados na aplicação do método. Dentre eles, destacam-se a NBR ISO 14040 (2014) e o Manual do International Reference Life Cycle Data System (ILCD), desenvolvido pela Comissão

124 Azevedo, L. D. de; Geraldi, M. S.; Ghisi, E. 
Europeia de Produção e Consumo Sustentável e Plano de Ação Sustentável em Política Industrial (RASHID; YUSOFF, 2015; VAN OOTEGHEM; XU, 2012).

Para o setor da construção civil, os estudos desenvolvidos abrangeram principalmente casas e edifícios residenciais e prédios comerciais (BUYLE; BRAET; AUDENAERT, 2013; RAMESH; PRAKASH; SHUKLA, 2010; RASHID; YUSOFF, 2015). Segundo Buyle, Braet e Audenaert (2013), das 34 avaliações publicadas no setor a partir do ano 2000, 26 delas foram aplicadas para edificações residenciais e duas para instituições de ensino. Para o setor da construção civil, a ACV abrange tradicionalmente dois aspectos principais: os materiais e a fase de operação das edificações (VAN OOTEGHEM; XU, 2012).

No Brasil, o Programa Minha Casa Minha Vida (PMCMV) facilita a construção de habitações de interesse social. Entretanto, os projetos utilizados não consideram os impactos ambientais com a sua construção, sendo replicados em diferentes zonas bioclimáticas e desenvolvidos sem a adoção de medidas de eficiência energética (MONTES, 2016). Além disso, sua qualidade é prejudicada pela busca da redução de custos e dos curtos prazos de entrega (LOPES, 2010). Nesse contexto, alguns estudos considerando o ciclo de vida dessas edificações foram desenvolvidos no país.

Caldas et al. (2016) utilizaram o consumo energia primária e emissões de $\mathrm{CO}_{2}$ como indicadores ambientais para avaliar o ciclo de vida de quatro sistemas de fachadas para habitações de interesse social. Os sistemas considerados foram o light steel framing, parede de concreto moldada no local, blocos de concreto estruturais e blocos cerâmicos estruturais. A fronteira do sistema estabelecida considerou as fases de extração e processamento e manutenção dos materiais e componentes. A vida útil considerada para a fase de manutenção foi de 50 anos. Considerando o ciclo de vida estudado, o sistema de parede de concreto apresentou menor consumo de energia e de emissões de $\mathrm{CO}_{2}$, sendo definido como o mais indicado para uso em habitações de interesse social (HIS).

Paulsen e Sposto (2013) analisaram todas as fases do ciclo de vida energético de uma edificação do programa Minha Casa Minha Vida localizada perto de Brasília. A edificação possui $48 \mathrm{~m}$ de área construída e, devido ao padrão da construção, não foi considerado o uso de ar-condicionado. A vida útil definida foi de 50 anos. O maior percentual de energia vem da extração e produção dos materiais, totalizando $41,5 \%$. No entanto, $41,1 \%$ da energia embutida é oriunda da manutenção ao longo do ciclo de vida. Para os materiais, o tijolo cerâmico foi o que apresentou maior influência no total de energia embutida, mas o valor para manutenção da pintura foi o maior devido à periodicidade da manutenção. Com isso, o elemento de maior demanda de energia embutida foi a parede da edificação. A energia de operação resultou em $68,9 \%$, sendo $45,5 \%$ devido ao consumo de eletricidade e $23,4 \%$ ao cozimento de alimentos. A energia embutida somou $30,1 \%$ da energia no ciclo de vida.

Caldas, Lira e Sposto (2017) avaliaram o ciclo de vida de duas habitações de interesse social de $46 \mathrm{~m}$. O escopo do estudo foi definido como do "berço ao portão com opções", considerando as fases de produção dos materiais, substituição e uso de energia para operação da edificação. O método utilizado foi o IMPACT $2002+$ e a vida útil escolhida foi de 50 anos. Foram consideradas todas as zonas bioclimáticas do país e as paredes foram alteradas entre alvenaria estrutural de blocos cerâmicos e painéis pré-moldados de concreto armado. O uso de ar-condicionado foi considerado em todos os ambientes de longa permanência. A fase de operação foi a mais significativa para todas as categorias de impacto. A alvenaria cerâmica obteve melhores cenários para o ciclo de vida considerado no estudo. Os resultados apresentaram variações significativas para o mesmo sistema construtivo em diferentes zonas bioclimáticas.

Diante do panorama do setor da construção civil no Brasil, é explícito que o impacto ambiental não é considerado na escolha de materiais e definição de envoltória para construções de interesse social. Do mesmo modo, é necessário considerar o desempenho térmico que a envoltória terá ao longo da vida útil da edificação.

Dessa forma, o objetivo principal deste estudo é selecionar um conjunto de componentes construtivos de parede e cobertura com menor impacto ambiental para uso em habitações de interesse social na região de Florianópolis. Para isso, foi utilizada simulação computacional para quantificar as horas de desconforto térmico e o consumo energético de cada conjunto, e a avaliação de ciclo de vida para mensurar os impactos potenciais de cada um. Com o estudo, busca-se ampliar o conhecimento relacionado ao potencial de impacto ambiental que a construção de habitações de interesse social representa para o Brasil. 


\section{Método}

O método desenvolvido consistiu em cinco etapas principais (Figura 1), detalhadas a seguir. A avaliação do ciclo de vida foi desenvolvida seguindo as etapas de definição do objetivo e escopo, análise de inventário, avaliação dos impactos e interpretação dos dados obtidos.

\section{Projeto arquitetônico modelo e definição dos sistemas construtivos}

Como o estudo desenvolvido é voltado para edificações na região da Grande Florianópolis, as exigências mínimas do Código de Obras e Edificações local foram cruzadas com as estabelecidas pelo Programa Minha Casa Minha Vida para definição da quantidade e tamanho dos cômodos.

Para o levantamento das características predominantes nos projetos arquitetônicos financiados pelo PMCMV na região, foi realizada uma busca no mercado local por meio de sites de compra e venda. Foram levantadas informações a respeito da localização, área total, quantidade e divisão dos cômodos e uso de aparelhos de refrigeração. Os projetos analisados apresentaram área total entre $50 \mathrm{~m}$ e $83 \mathrm{~m}$ e, em sua maioria, dois dormitórios e um banheiro. A sala de estar e a cozinha não eram integradas somente em um dos projetos estudados, e em todos os projetos a área de serviço não tinha um cômodo exclusivo. Todas as edificações nas quais foi possível avaliar o uso de ar-condicionado apresentavam pontos de instalação elétrica nos quartos e nenhum na sala de estar/cozinha. Sobre a orientação do projeto, três comentaram ter boa ventilação e insolação, sendo todos da mesma construtora. A Figura 2 apresenta a planta baixa desenvolvida. O projeto desenvolvido apresenta similaridade com as tipologias identificadas por Triana, Lamberts e Sassi (2015).

Para definir quais materiais seriam utilizados foram considerados dois critérios de pesquisa: frequência de uso nas edificações construídas na cidade de Florianópolis por meio do financiamento do PMCMV e frequência de uso em escritórios de arquitetura que aplicam conceitos de arquitetura sustentável. A identificação dos materiais que seguem os critérios adotados foi feita por meio de revisão bibliográfica e pesquisa em escritórios de arquitetura locais, por meio de consulta aos seus sites e, quando necessário, contato direto com os escritórios. Além disso, consideraram-se somente paredes de vedação que não exigissem alteração no projeto estrutural da edificação.

Os projetos da estrutura e das instalações hidráulicas e elétricas foram considerados iguais para todos os casos. Essa padronização permite que suas influências sejam desconsideradas na avaliação do ciclo de vida, que será utilizada de forma comparativa entre os conjuntos. Com isso, o levantamento quantitativo de materiais para esses sistemas não foi considerado.

Segundo Ghisi et al. (2015), o principal componente construtivo de parede utilizado em habitações construídas pelo financiamento do PMCMV é o de bloco cerâmico. O percentual levantado indica que $75 \%$ das áreas secas e $95 \%$ das áreas molhadas foram construídas com esse componente construtivo. Por meio de consulta aos escritórios de arquitetura da região que trabalham com o conceito de arquitetura sustentável, foi possível perceber que todos os escritórios que foram consultados apresentam a terra como alternativa de matéria-prima para o material de vedação. A Figura 3 apresenta as duas paredes selecionadas para estudo.

Figura 1 - Fluxograma do método

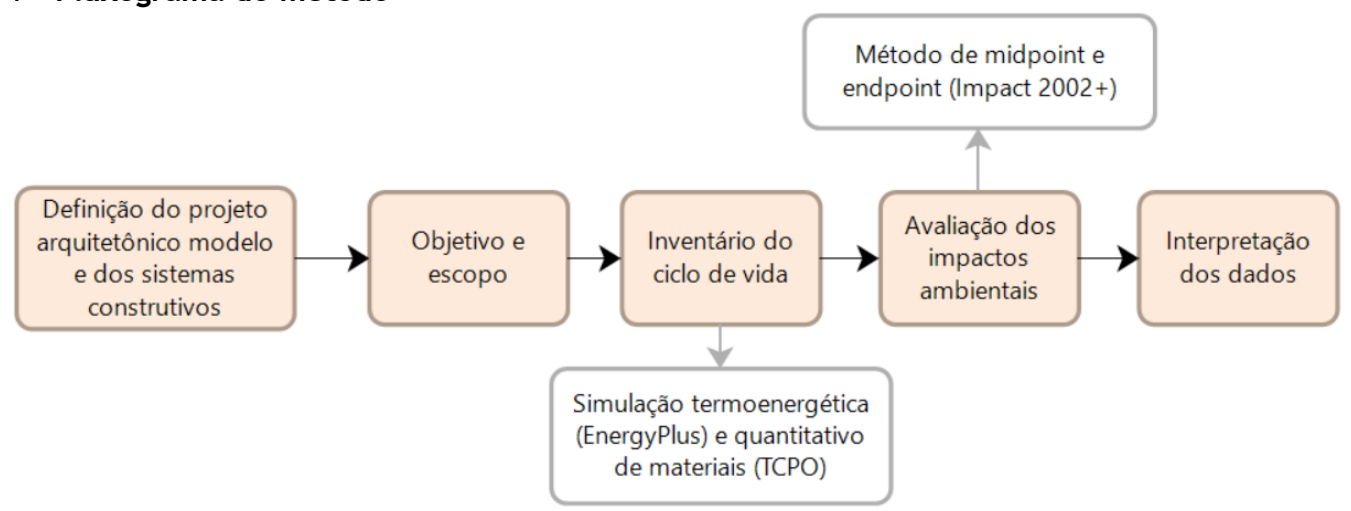

126 Azevedo, L. D. de; Geraldi, M. S.; Ghisi, E. 
Figura 2 - Planta baixa definida para o projeto arquitetônico modelo
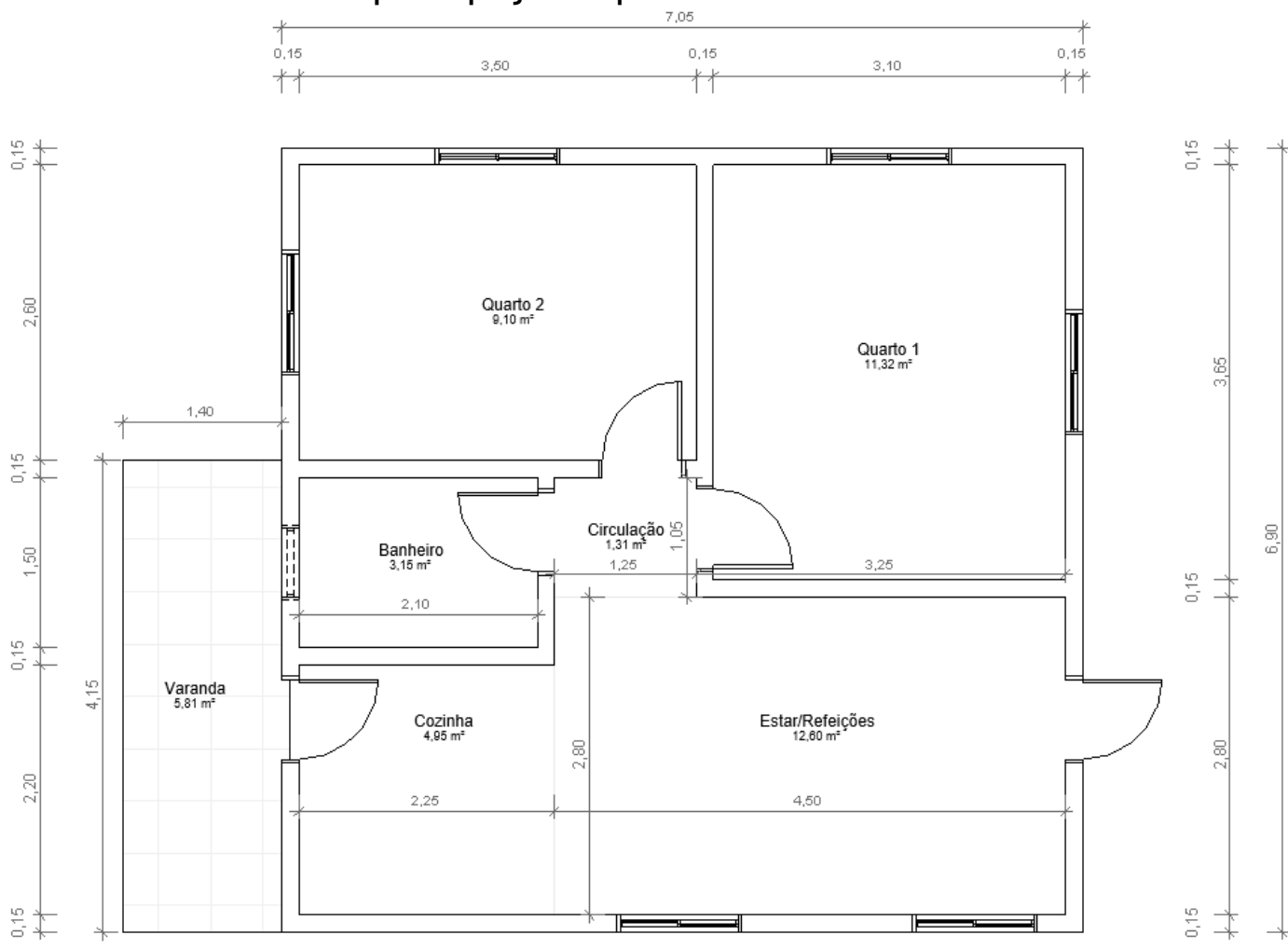

Figura 3 - Paredes selecionadas para o estudo

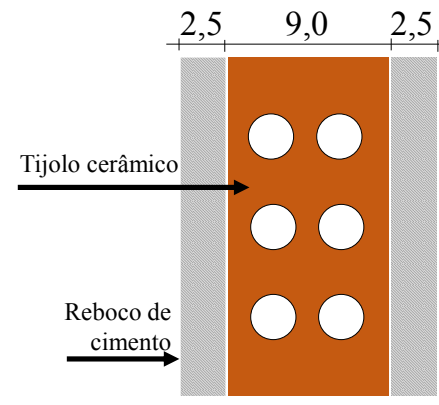

Tijolo cerâmico de 6 furos com reboco

$(\mathrm{cm})$

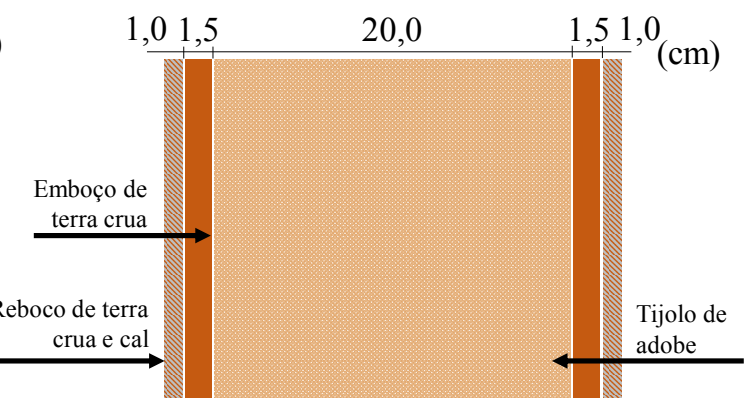

Tijolo de Adobe com emboço e reboco

Os tipos de cobertura analisados são compostos pela telha e pelo forro ou laje. As características desses elementos foram definidas como sendo aquelas que apresentaram maior frequência de uso em Ghisi et al. (2015). A estrutura do telhado foi considerada igual para todos os casos, não precisando ser contabilizada para a ACV por ser igual para todos os casos comparados entre si. A inclinação escolhida para a cobertura foi de 32\%. Para avaliar a influência do uso de laje para fechamento horizontal da edificação no ciclo de vida, considerou-se a laje maciça em um dos componentes construtivos. O Quadro 1 apresenta a composição final das coberturas consideradas.

\section{Objetivo e escopo}

O objetivo da avaliação do ciclo de vida é determinar os impactos sobre o meio ambiente de cada caso dentro das fronteiras estabelecidas, tornando possível a comparação entre os resultados obtidos. Os critérios utilizados para definição da fronteira do sistema consideraram as limitações do trabalho e o objetivo do estudo. 
Quadro 1 - Coberturas selecionadas para avaliação

\begin{tabular}{|c|c|c|}
\hline Tipo & Telha & Forro \\
\hline 1 & Cerâmica & Madeira \\
\hline 2 & Cerâmica & Laje maciça de concreto $(10 \mathrm{~cm})$ \\
\hline
\end{tabular}

Com isso, as fases de extração de matéria prima, fabricação dos produtos, transporte e operação da edificação foram consideradas. Manutenção, reparos e reformas não foram englobados na fase de operação por não haver dados consistentes relacionados à manutenção e duração da parede de adobe. Para a construção da edificação foram considerados os materiais para a construção da edificação e as taxas de desperdício de materiais. A demanda relacionada ao processo construtivo foi desconsiderada, devido ao fato de esse tipo de edificação ser majoritariamente construído de forma manual. O descarte final dos materiais e o impacto das infraestruturas, como construção das fábricas e máquinas utilizadas não foram considerados.

Como não existe nenhuma norma brasileira específica para a ACV de edificações, segundo os critérios definidos pela EN 15978, norma europeia que apresenta o método de cálculo para a avaliação do desempenho ambiental de edifícios, o escopo da ACV desenvolvida pode ser caracterizado como de "berço ao portão com opções" (BUILDING..., 2018). Para essa categoria, somente são mandatórias a fase de préuso dos materiais, que envolve o fornecimento de matéria-prima, transporte e a fabricação dos produtos utilizados.

A vida útil escolhida foi de 50 anos, conforme adotado em outros trabalhos na literatura (BUYLE; BRAET; AUDENAERT, 2013; CALDAS et al., 2016; PAULSEN; SPOSTO, 2013). Considerou-se como unidade funcional para o desenvolvimento da ACV a construção e operação de uma edificação de 48,24 m, com ocupação de quatro habitantes ao longo de toda vida útil. O sistema de produto definido considerou cada componente construtivo como um processo. A Figura 4 apresenta o sistema de produto e a fronteira do sistema.

\section{Inventário do ciclo de vida (ICV)}

O levantamento das áreas foi realizado computacionalmente por meio do programa Revit, evitando o uso de estimativas. A quantificação dos insumos considerados no inventário foi baseada nas composições unitárias das Tabelas de Composições de Preços para Orçamentos (TABELA..., 2010), em manuais de boas práticas referentes aos componentes construtivos e em pesquisa aos fornecedores locais para informações sobre os produtos.

A produção dos tijolos de adobe foi considerada de maneira artesanal no local da obra. Seu desperdício no processo construtivo não foi considerado, visto que os tijolos quebrados podem ser refeitos com o aproveitamento dos materiais do próprio tijolo. Para o tijolo cerâmico, o desperdício considerado foi de 5\% (TCPO, 2010).

Para a argamassa de assentamento das paredes de bloco cerâmico foi considerado o traço de 1:2:9 de cimento, cal hidratada e areia e, para a parede de adobe, foi considerado traço de 7:3 de solo e serragem, com volume de $23 \%$ de água (CHRISTOFOROU et al., 2016). A distância de distribuição dos materiais foi medida pela mediana dos três principais fornecedores de cada material para a região central de Florianópolis.

A energia consumida ao longo da operação da edificação foi obtida por meio das simulações computacionais desenvolvidas com uso do EnergyPlus para cada caso analisado. Foram considerados sistemas de condicionamento de ar tipo split com função aquecimento e resfriamento nos ambientes de longa permanência (quartos e sala/cozinha) de forma a considerar o consumo máximo provável. Teve-se como resultado (output) o consumo total em $\mathrm{kWh}$. A rotina de operação do sistema de condicionamento de ar adotada foi associada à rotina de ocupação com setpoint definido para $20{ }^{\circ} \mathrm{C}$ e $24{ }^{\circ} \mathrm{C}$.

Além da variação dos componentes construtivos selecionados, a orientação da edificação foi alterada de $90^{\circ}$ em $90^{\circ}$ no sentido horário, com o objetivo de considerar diferentes orientações para o projeto. Com a consideração dos diferentes componentes e a variação da orientação da edificação, dezesseis modelos foram simulados. A Figura 5 apresenta as orientações e o valor angular considerado para cada uma delas.

Adotou-se pé-direito de 2,60 m. O ambiente da área de serviço, por ser externo, não foi modelado como um cômodo. Entretanto, o telhado foi definido como elemento de sombreamento na fachada, conforme apresentado na Figura 6. 
Figura 4 - Sistema de produto e fronteira do sistema considerado para a ACV

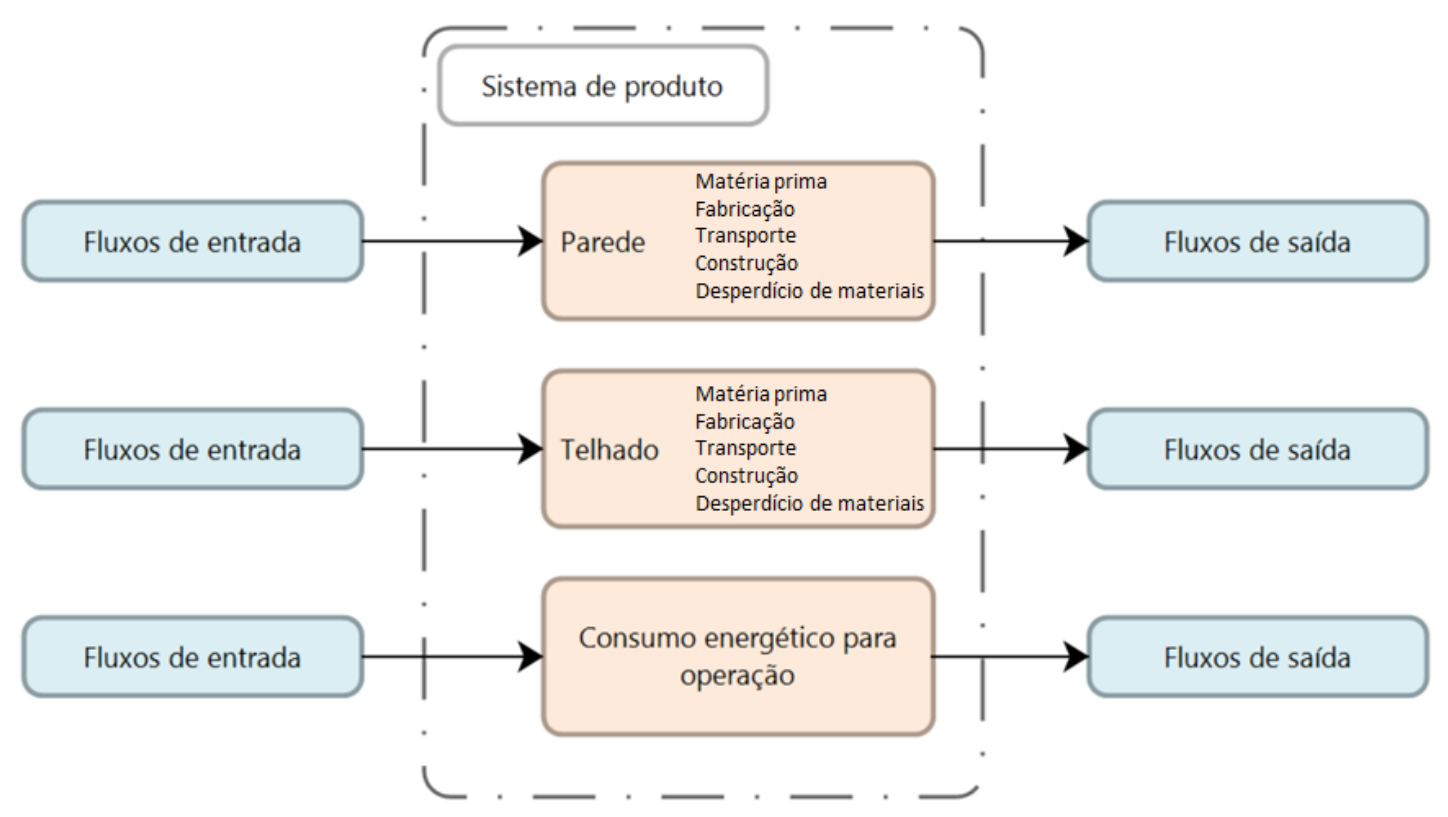

Figura 5 - Orientações e nomenclaturas adotadas para simulação da edificação

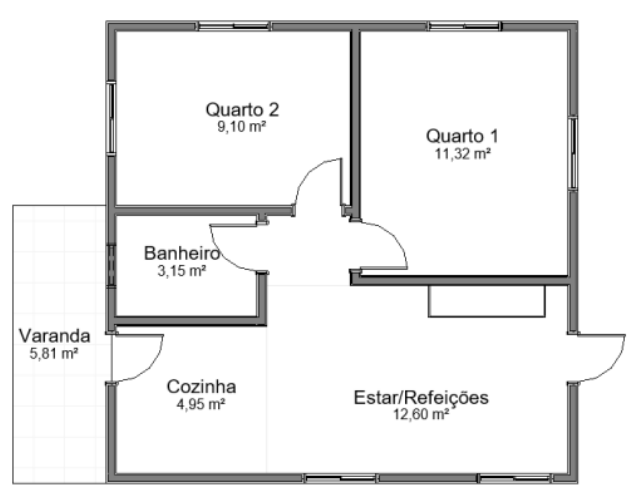

(a) Orientação $0^{\circ}$

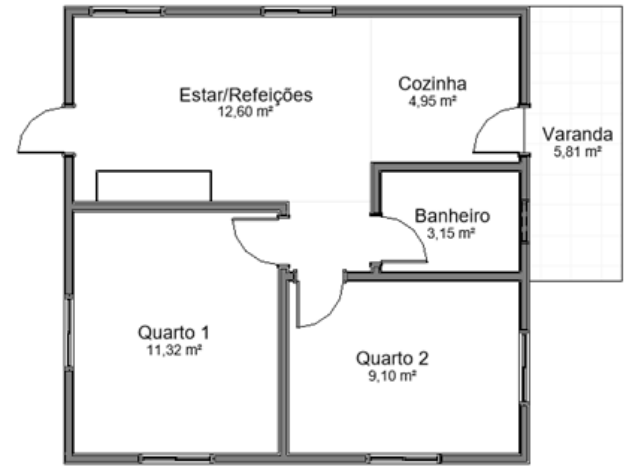

(c) Orientação $180^{\circ}$

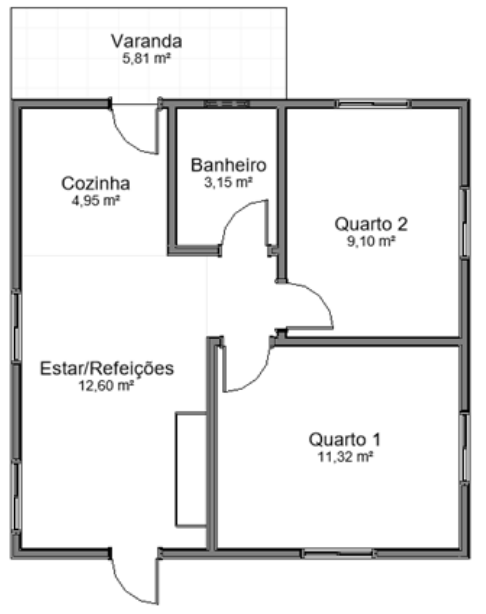

(b) Orientação $90^{\circ}$

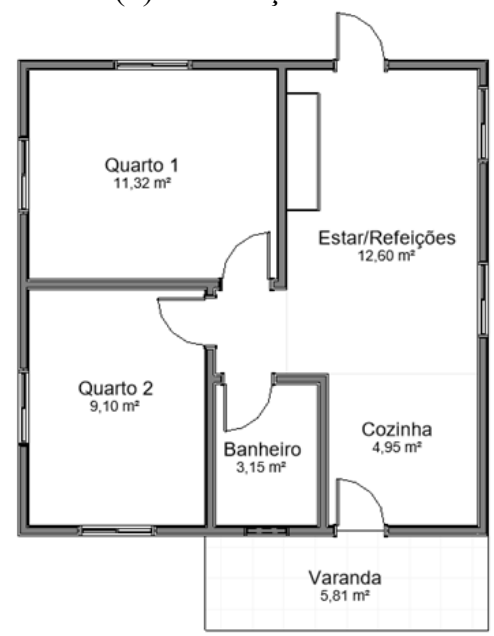

(d) Orientação $270^{\circ}$ 
Figura 6 - Modelo da edificação utilizado para a simulação computacional

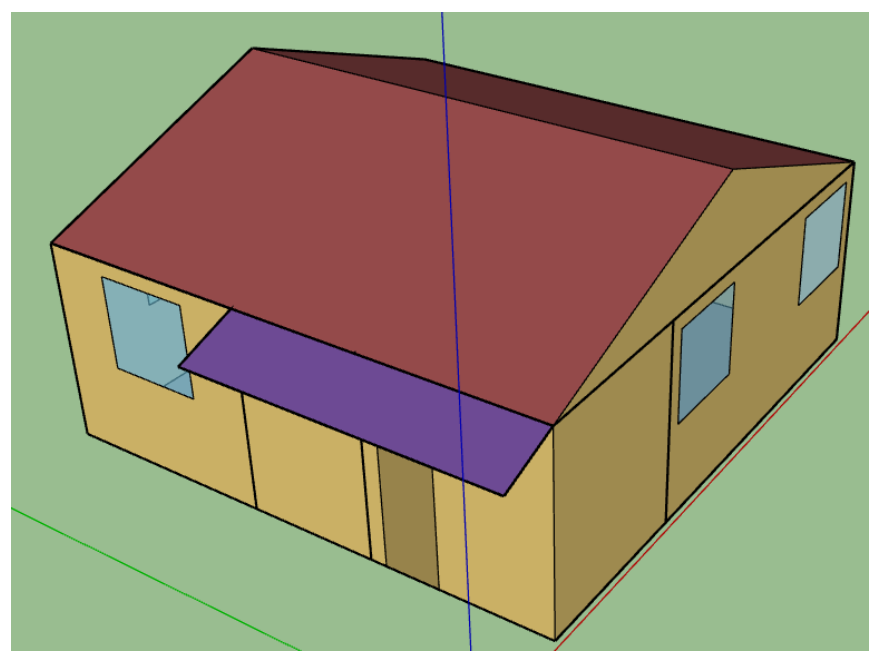

O padrão de ocupação, de uso de equipamentos, de iluminação e de abertura de esquadrias foi definido por meio do relatório publicado por Ghisi et al. (2015). Os dados dos materiais construtivos para uso na simulação (espessura, condutividade, densidade, absortância térmica, absortância solar e absortância visível) foram obtidos por meio de revisão bibliográfica e estão apresentados nas Tabelas 1 e 2 . Como não foi avaliada a influência da mudança da cor utilizada nas paredes, as absortâncias solar e visível foram fixadas em $35 \%$. Esse valor pode equivaler às cores branca, azul, verde, laranja, amarelo, salmão ou bege (GHISI et al., 2015).

\section{Avaliação de impacto do ciclo de vida (AICV)}

O programa utilizado para a avaliação de impacto do ciclo de vida (AICV) foi o SimaPro na versão 9.0.0.47. O método de cálculo definido para uso foi a versão 2.15 do IMPACT 2002+, conforme utilizado por Souza et al. (2016) e Caldas, Lira e Sposto (2017). Por meio dele são considerados os métodos clássicos e os mais recentes de previsão de impacto. O método clássico quantifica os impactos considerados como midpoint, que compõem o início da cadeia de causa e efeito. As abordagens utilizadas recentemente caracterizam os impactos conhecidos como endpoint, agrupando os impactos em categorias de dano (HUMBERT et al., 2012).

O método foi definido por ser um dos mais utilizados para pesquisas no setor e apresentar tanto categorias de impacto como categorias de dano. O Quadro 2 apresenta as categorias de impacto obtidas como resultado da fase de AICV por meio da aplicação do método IMPACT 2002+. O banco de dados utilizado foi o Ecoinvent 3.5 , sem a adaptação de datasets.

Para confirmar a escolha do conjunto com menor impacto, a ACV foi refeita considerando o uso de outro método de AICV. O método utilizado foi o ReCiPe Midpoint hierárquico versão 1.03. Esse método foi considerado porque, assim como o IMPACT 2002+, é um dos mais utilizados em estudos da área no setor da construção civil e apresenta tanto categorias de impacto como de dano. A perspectiva hierarquista foi utilizada pelo fato de seus mecanismos de impactos serem baseados em consenso científico (NATIONAL..., 2017). O Quadro 3 apresenta as categorias de impacto consideradas pelo método e as suas unidades.

\section{Interpretação dos dados de impacto ambiental do ciclo de vida}

A interpretação dos dados obtidos com a avaliação do ciclo de vida ocorreu em três etapas principais. Inicialmente, foram considerados os impactos oriundos somente dos materiais ao longo do ciclo de vida. Para facilitar a visualização gráfica, os valores obtidos são apresentados de forma relativa ao maior valor de cada categoria de impacto.

$\mathrm{Na}$ segunda etapa é considerada toda a fronteira do sistema. Os resultados são apresentados seguindo o padrão da análise dos materiais. 
Por fim, considera-se os resultados obtidos por meio da aplicação do método ReCiPe para toda a fronteira estabelecida pelo estudo. Foram desconsiderados processos de ponderação ou agrupamento. O processamento dos dados foi desenvolvido por meio do software Excel.

\section{Resultados e discussões}

\section{Inventário do Ciclo de Vida (ICV)}

O inventário do estudo consiste em dois resultados principais: o quantitativo de materiais e os resultados da simulação computacional para a estimativa de consumo energético anual. O quantitativo definido para cada sistema construtivo é apresentado na Tabela 3. A unidade de cada material foi definida por meio de consulta ao banco de dados utilizado.

Tabela 1 - Características térmicas dos materiais utilizados nas coberturas

\begin{tabular}{c|c|c|c|c|c|c}
\hline \multicolumn{2}{c|}{$\begin{array}{c}\text { Componentes } \\
\text { construtivos }\end{array}$} & $\begin{array}{c}\text { Espessura } \\
(\mathbf{m})\end{array}$ & $\begin{array}{c}\text { Condutividade } \\
\text { térmica }(\mathbf{W} / \mathbf{m} . \mathbf{K})\end{array}$ & $\begin{array}{c}\text { Densidade } \\
\left(\mathbf{k g} / \mathbf{m}^{\mathbf{3}}\right)\end{array}$ & $\begin{array}{c}\text { Calor específico } \\
(\mathbf{J} / \mathbf{k g} . \mathbf{K})\end{array}$ & $\begin{array}{c}\text { Absortância } \\
\text { solar/visível }\end{array}$ \\
\hline Telha & Cerâmica & 0,01 & 1,05 & 2000 & 920 & 0,7 \\
Forro & Madeira & 0,01 & 0,15 & 600 & 1340 & 0,7 \\
Forro & Concreto & 0,10 & 1,15 & 2200 & 1000 & 0,7 \\
\hline
\end{tabular}

Fonte: baseado em Weber et al. (2017).

Tabela 2 - Características térmicas dos materiais utilizados nas paredes

\begin{tabular}{l|l|c|c|c|c}
\hline $\begin{array}{c}\text { Componentes } \\
\text { construtivos }\end{array}$ & \multicolumn{1}{|c|}{ Camadas } & $\begin{array}{c}\text { Espessura } \\
(\mathbf{m})\end{array}$ & $\begin{array}{c}\text { Condutividade } \\
\text { térmica }(\mathbf{W} / \mathbf{m} . \mathbf{K})\end{array}$ & $\begin{array}{c}\text { Densidade } \\
\left(\mathbf{k g} / \mathbf{m}^{\mathbf{3}}\right)\end{array}$ & $\begin{array}{c}\text { Calor específico } \\
(\mathbf{J} / \mathbf{k g} . \mathbf{K})\end{array}$ \\
\hline \multirow{3}{*}{ Bloco Cerâmico } & Argamassa interna & 0,025 & 1,15 & 2000 & 1000 \\
& Cerâmico (9x19x19) & 0,013 & 0,9 & 1600 & 920 \\
& Argamassa externa & 0,025 & 1,15 & 2000 & 1000 \\
\hline \multirow{5}{*}{ Bloco de Adobe } & Reboco (cal) & 0,01 & 0,75 & 1600 & 200 \\
& Argamassa (mista) & 0,015 & 0,82 & 1700 & 828 \\
& Tijolo de adobe & 0,20 & 0,82 & 1700 & 828 \\
& Argamassa (mista) & 0,015 & 0,82 & 1700 & 828 \\
& Reboco (cal) & 0,01 & 0,75 & 1600 & 200 \\
\hline
\end{tabular}

Fonte: ${ }^{1}$ Weber et al. (2017), ${ }^{2}$ Programas de Empleo y Juventud (2009) e ${ }^{3}$ Meneses (2010).

Quadro 2 - Categorias de impacto obtidas na avaliação do ciclo de vida e suas respectivas unidades

\begin{tabular}{|l|l|}
\hline Categorias de impacto (midpoint) & \multicolumn{1}{|c|}{ Unidade } \\
\hline Carcinógenos & DALY \\
\hline Não carcinógenos & DALY \\
\hline Inorgânicos respiráveis & DALY \\
\hline Radiação ionizante & DALY \\
\hline Depleção da camada de ozônio & DALY \\
\hline Orgânicos respiráveis & $\mathrm{DALY}$ \\
\hline Ecotoxicidade aquática & $\mathrm{PDF}^{*} \mathrm{~m}$ *ano \\
\hline Ecotoxicidade terrestre & $\mathrm{PDF}^{*} \mathrm{~m}$ *ano \\
\hline Acidificação/eutrofização terrestre & $\mathrm{PDF}^{*} \mathrm{~m}$ *ano \\
\hline Ocupação do solo & $\mathrm{PDF}^{*} \mathrm{~m} *$ ano \\
\hline Potencial de aquecimento global & $\mathrm{kg} \mathrm{CO}_{2}$ eq \\
\hline Energia não renovável & $\mathrm{MJ}$ primário \\
\hline Extração mineral & $\mathrm{MJ}$ primário \\
\hline
\end{tabular}

Fonte: baseado em Humbert et al. (2012).

Nota: DALY representa o valor de anos de vida ajustados por incapacidade, considerando tanto os anos de vida por falecimento prematuro quanto os anos de vida com qualidade reduzida devido a doenças. PDF $^{*} \mathrm{~m}^{2 *}$ ano representa a fração potencial de espécies desaparecidas em um $\mathrm{m}^{2}$ ao longo de um ano. 
Quadro 3 - Categorias de impacto, e suas respectivas unidades, obtidas na avaliação do ciclo de vida por meio do método ReCiPe

\begin{tabular}{|l|l|}
\hline \multicolumn{1}{|c|}{ Categorias de impacto (midpoint) } & \multicolumn{1}{c|}{ Unidade } \\
\hline Aquecimento global & $\mathrm{kg} \mathrm{CO}$ eq \\
\hline Depleção estratosférica de ozônio & $\mathrm{kg} \mathrm{CFC11} \mathrm{eq}$ \\
\hline Radiação ionizante & $\mathrm{kBq}$ Co-60 eq \\
\hline Formação de ozônio, Saúde humana & $\mathrm{kg} \mathrm{NOx} \mathrm{eq}$ \\
\hline Formação de partículas finas & $\mathrm{kg} \mathrm{PM2.5} \mathrm{eq}$ \\
\hline Formação de ozônio, ecossistemas terrestres & $\mathrm{kg} \mathrm{NOx} \mathrm{eq}$ \\
\hline Acidificação terrestre & $\mathrm{kg} \mathrm{SO} 2$ eq \\
\hline Eutrofização de água doce & $\mathrm{kg} \mathrm{P} \mathrm{eq}$ \\
\hline Eutrofização marinha & $\mathrm{kg} \mathrm{N} \mathrm{eq}$ \\
\hline Ecotoxicidade terrestre & $\mathrm{kg} \mathrm{1,4-DCB}$ \\
\hline Ecotoxicidade em água doce & $\mathrm{kg} \mathrm{1,4-DCB}$ \\
\hline Ecotoxicidade marinha & $\mathrm{kg} \mathrm{1,4-DCB}$ \\
\hline Toxicidade cancerígena humana & $\mathrm{kg} \mathrm{1,4-DCB}$ \\
\hline Toxicidade não carcinogênica humana & $\mathrm{kg} \mathrm{1,4-DCB}$ \\
\hline Uso da terra & $\mathrm{m}^{2} \mathrm{a}$ crop eq \\
\hline Escassez de recursos minerais & $\mathrm{kg} \mathrm{Cu} \mathrm{eq}$ \\
\hline Escassez de recursos fósseis & $\mathrm{kg}$ óleo eq \\
\hline Consumo de água & $\mathrm{m}^{3}$ \\
\hline
\end{tabular}

Tabela 3 - Quantitativo dos materiais utilizados para cada tipo de parede

\begin{tabular}{|c|c|c|}
\hline Sistema construtivo & Material & Quantidade \\
\hline Forro de madeira e telha cerâmica & $\begin{array}{l}\text { Madeira }(\mathrm{m}) \\
\text { Telha cerâmica }(\mathrm{kg}) \\
\text { Cimento }(\mathrm{kg}) \\
\text { Cal hidratada }(\mathrm{kg}) \\
\text { Areia }(\mathrm{kg}) \\
\text { Água }(\mathrm{kg}) \\
\text { Transporte }(\mathrm{tkm})\end{array}$ & $\begin{array}{r}4,05 \\
2793,60 \\
40,32 \\
114,24 \\
423,36 \\
76,61 \\
594,97\end{array}$ \\
\hline Forro de laje maciça e telha cerâmica & $\begin{array}{l}\text { Cimento }(\mathrm{kg}) \\
\text { Areia }(\mathrm{kg}) \\
\text { Aço }(\mathrm{kg}) \\
\text { Água }(\mathrm{kg}) \\
\text { Telha cerâmica }(\mathrm{kg}) \\
\text { Cal hidratada }(\mathrm{kg}) \\
\text { Madeira }(\mathrm{kg}) \\
\text { Transporte }(\mathrm{tkm})\end{array}$ & $\begin{array}{r}472,80 \\
2441,60 \\
5341,13 \\
891,47 \\
2793,60 \\
114,24 \\
555,82 \\
3431,18 \\
\end{array}$ \\
\hline Alvenaria Cerâmica & $\begin{array}{l}\text { Tijolo (un) } \\
\text { Cimento }(\mathrm{kg}) \\
\text { Cal hidratada }(\mathrm{kg}) \\
\text { Areia }(\mathrm{kg}) \\
\text { Água }(\mathrm{kg}) \\
\text { Barra de aço }(\mathrm{kg}) \\
\text { Tinta latex acrílica }(\mathrm{kg}) \\
\text { Transporte }(\mathrm{tkm})\end{array}$ & $\begin{array}{r}2327,00 \\
839,76 \\
2192,76 \\
1529,09 \\
1306,38 \\
199,76 \\
31,80 \\
2606,46 \\
\end{array}$ \\
\hline Alvenaria de adobe & $\begin{array}{l}\text { Argila }(\mathrm{kg}) \\
\text { Terra }(\mathrm{kg}) \\
\text { Serragem }(\mathrm{kg}) \\
\text { Água }(\mathrm{kg}) \\
\text { Areia }(\mathrm{kg}) \\
\text { Cal hidratada }(\mathrm{kg}) \\
\text { Barra de aço }(\mathrm{kg}) \\
\text { Cal pintura }(\mathrm{kg}) \\
\text { Transporte }(\mathrm{tkm})\end{array}$ & $\begin{array}{r}4898,35 \\
29275,87 \\
1358,15 \\
12570,98 \\
8342,88 \\
2296,19 \\
197,01 \\
26,95 \\
1583,26\end{array}$ \\
\hline
\end{tabular}


Os materiais utilizados na ACV foram definidos conforme processos existentes no Ecoinvent 3.5. O Quadro 4 apresenta os processos utilizados para cada tipo de dado de entrada utilizado para uso no estudo.

A simulação computacional, considerando os quatro conjuntos de sistemas construtivos e as quatro orientações do projeto resultaram e dezesseis estimativas de consumo energético anual.

A Tabela 4 apresenta os resultados obtidos. Para utilização na $\mathrm{ACV}$, considerou-se a orientação de $90^{\circ}$, que apresentou os maiores valores de consumo.

Em relação aos consumos anuais, os maiores valores em todas as orientações foram do conjunto de parede de tijolo cerâmico com forro de madeira, e os menores, do conjunto de parede de adobe e laje maciça. No entanto, as diferenças não são significativas. Considerando o consumo médio das quatro orientações e o conjunto de parede de adobe e laje maciça como referência, observou-se que o conjunto de parede de tijolo cerâmico e forro de madeira apresentou consumo 8,3\% maior, o conjunto de parede de adobe e forro de madeira apresentou consumo 4,1\% maior, e o conjunto de parede de tijolo cerâmico e laje maciça apresentou consumo apenas $2,2 \%$ maior.

\section{Avaliação de impacto do ciclo de vida (AICV)}

O método de AICV definido para o estudo foi o IMPACT 2002+. São apresentados inicialmente somente os materiais e, em seguida, toda a fronteira estabelecida para o sistema de produto. A Tabela 5 apresenta os resultados obtidos para cada categoria de impacto considerando somente os materiais e a Tabela 6 considerando todo o ciclo de vida. A interpretação dos resultados é apresentada na fase de interpretação do ciclo de vida.

\section{Interpretação do impacto ambiental do ciclo de vida}

A avaliação do ciclo de vida aqui aplicada caracteriza-se como análise de berço ao portão com opções. Inicialmente foram analisados os impactos ambientais somente dos materiais e, em seguida, de toda a fronteira definida para o ciclo de vida. Por fim, o ciclo de vida foi calculado considerando o uso do método ReCiPe para validação dos resultados.

Quadro 4 - Dados de entrada e os processos equivalentes utilizados da base de dados do Ecoinvent

\begin{tabular}{|l|l|}
\hline \multicolumn{1}{|c|}{ Dado de entrada } & \multicolumn{1}{c|}{ Processo no Ecoinvent } \\
\hline Energia elétrica & Eletricity, low voltage $\{$ BR $\}$ \\
\hline Madeira & Sawnwood, board, hardwood, dried $(u=10 \%)$, planed $\{$ RoW $\}$ \\
\hline Telha cerâmica & Ceramic tile $\{$ RoW $\}$ \\
\hline Cimento & Cement, Portland $\{$ RoW $\}$ \\
\hline Cal hidratada & Lime, hydrated, loose weight $\{$ RoW $\}$ \\
\hline Areia & Sand $\{$ RoW $\}$ \\
\hline Água & Tap water, conventional treatment $\{$ RoW $\}$ \\
\hline Transporte & Transport, freight, lorry $3.5-7.5$ metric ton \\
\hline Aço & Reinforcing steel $\{$ RoW $\}$ \\
\hline Tijolo & Clay Brick $\{$ RoW $\}$ \\
\hline Tinta latex acrílica & Alkyd paint, white, without solvent, in $60 \%$ solution state $\{$ RoW $\}$ \\
\hline Argila & Clay $\{$ RoW $\}$ \\
\hline Terra & Sand $\{$ RoW $\}$ \\
\hline Serragem & Saw dust, wet, measured as dry mass $\{$ RoW $\}$ \\
\hline
\end{tabular}

Tabela 4 - Consumo energético anual para cada orientação

\begin{tabular}{l|c|c|c|c}
\hline \multirow{2}{*}{ Componentes construtivos } & \multicolumn{4}{|c}{ Consumo energético anual (kWh) } \\
\cline { 2 - 5 } & $\mathbf{0}^{\circ}$ & $\mathbf{9 0}^{\circ}$ & $\mathbf{1 8 0}^{\circ}$ & $\mathbf{2 7 0}^{\circ}$ \\
\hline Tijolo cerâmico/Forro madeira & 4092 & 4119 & 4119 & 4153 \\
Tijolo cerâmico/Laje & 3850 & 3908 & 3892 & 3903 \\
Adobe/Forro madeira & 3939 & 3969 & 3969 & 3969 \\
Adobe/Laje & 3769 & 3828 & 3814 & 3814 \\
\hline
\end{tabular}


Tabela 5 - Valores de impacto obtidos para os materiais por categoria de impacto conforme o método IMPACT 2002+

\begin{tabular}{l|c|c|c|c}
\hline \multirow{2}{*}{ Categoria de impacto } & \multicolumn{4}{c}{ Modelo } \\
\cline { 2 - 5 } & $\begin{array}{c}\text { Tijolo cerâmico/ } \\
\text { Forro madeira }\end{array}$ & $\begin{array}{c}\text { Tijolo cerâmico/ } \\
\text { Laje }\end{array}$ & $\begin{array}{c}\text { Adobe/ Forro } \\
\text { madeira }\end{array}$ & $\begin{array}{c}\text { Adobe/ } \\
\text { Laje }\end{array}$ \\
\hline Carcinógenos (DALY) & 0,00024 & 0,00555 & 0,00017 & 0,00548 \\
\hline Não carcinógenos (DALY) & 0,00032 & 0,01011 & 0,00024 & 0,01004 \\
\hline Inorgânicos respiráveis (DALY) & 0,00794 & 0,17099 & 0,00683 & 0,16988 \\
\hline Radiação ionizante (DALY) & 0,000007 & 0,000179 & 0,000005 & 0,000177 \\
\hline $\begin{array}{l}\text { Depleção da camada de ozônio } \\
\text { (DALY) }\end{array}$ & 0,00000061 & 0,00000796 & 0,00000045 & 0,000008 \\
\hline Orgânicos respiráveis (DALY) & 0,0000062 & 0,0002865 & 0,0000047 & 0,000285 \\
\hline $\begin{array}{l}\text { Ecotoxicidade aquática } \\
\text { (PDF*m *ano) }\end{array}$ & 35,62 & 1197,57 & 25,25 & 1187,21 \\
\hline $\begin{array}{l}\text { Ecotoxicidade terrestre } \\
\text { (PDF*m *ano) }\end{array}$ & 1738,25 & 64941,17 & 1369,70 & 64572,63 \\
\hline $\begin{array}{l}\text { Acidificação/eutrofização terrestre } \\
\text { (PDF*m *ano) }\end{array}$ & 120,92 & 2760,24 & 84,80 & 2724,12 \\
\hline Ocupação do solo (PDF*m *ano) & 1660,44 & 207054,83 & 1750,34 & 207144,72 \\
\hline $\begin{array}{l}\text { Potencial de aquecimento global (kg } \\
\text { CO }{ }_{2} \text { eq) }\end{array}$ & 6658,02 & 83007,02 & 4766,33 & 81115,33 \\
\hline Energia não renovável (MJ primário) & 66009,78 & 1137014,41 & 47673,47 & 1118678,1 \\
\hline Extração mineral (MJ primário) & 253,30 & 4243,18 & 202,61 & 4192,49 \\
\hline
\end{tabular}

Tabela 6 - Valores de impacto obtidos para todo o ciclo de vida por categoria de impacto conforme o método IMPACT 2002+

\begin{tabular}{l|c|c|c|c}
\hline \multicolumn{1}{c|}{ Categoria de impacto } & \multicolumn{4}{c}{ Modelo } \\
\cline { 2 - 5 } & $\begin{array}{c}\text { Tijolo cerâmico/ } \\
\text { Forro madeira }\end{array}$ & $\begin{array}{c}\text { Tijolo cerâmico/ } \\
\text { Laje }\end{array}$ & $\begin{array}{c}\text { Adobe/ Forro } \\
\text { madeira }\end{array}$ & $\begin{array}{c}\text { Adobe/ } \\
\text { Laje }\end{array}$ \\
\hline Carcinógenos (DALY) & 0,00491 & 0,00998 & 0,00484 & 0,00991 \\
\hline Não carcinógenos (DALY) & 0,00140 & 0,01114 & 0,00132 & 0,01106 \\
\hline Inorgânicos respiráveis (DALY) & 0,0475 & 0,2085 & 0,0464 & 0,2075 \\
\hline Radiação ionizante (DALY) & 0,000131 & 0,000297 & 0,000130 & 0,000296 \\
\hline Depleção da camada de ozônio (DALY) & 0,00000514 & 0,00001226 & 0,00000498 & 0,000012 \\
\hline Orgânicos respiráveis (DALY) & 0,00002225 & 0,00030179 & 0,00002083 & 0,00030 \\
\hline Ecotoxicidade aquática (PDF*m *ano) & 164,9 & 1320,2 & 154,5 & 1310 \\
\hline Ecotoxicidade terrestre (PDF*m *ano) & 6496,2 & 69455,3 & 6127,7 & 69090 \\
\hline $\begin{array}{l}\text { Acidificação/eutrofização terrestre } \\
\text { (PDF*m *ano) }\end{array}$ & 750,9 & 3358,0 & 714,8 & 3322 \\
\hline Ocupação do solo (PDF*m *ano) & 1875,4 & 207258,8 & 1965,3 & 207349 \\
\hline $\begin{array}{l}\text { Potencial de aquecimento global (kg } \\
\text { CO eq) }\end{array}$ & 54044,4 & 127964,9 & 52152,7 & 126105 \\
\hline Energia não renovável (MJ primário) & 750851,7 & 1786759,8 & 732515,4 & 1768885 \\
\hline Extração mineral (MJ primário) & 962,0 & 4915,5 & 911,3 & 4865 \\
\hline
\end{tabular}

Para facilitar a visualização, os valores de impacto de cada categoria estão apresentados em percentual, sendo $100 \%$ o maior valor obtido para cada uma. A Figura 7 apresenta os valores percentuais.

Entre as paredes analisadas, o impacto da utilização dos materiais na edificação foi menor para a parede de adobe em todas as categorias de impacto. Em relação ao forro e à laje maciça, o impacto do uso da laje foi maior em todas as categorias de impacto, sendo o cimento o principal influenciador desse resultado.

A parede de tijolo de adobe apresentou, para a maioria das categorias, valor menor de impacto, ou seja, o seu impacto foi de $50,2 \%$ a $68,4 \%$ do valor de impacto da parede de tijolo cerâmico. Somente para a categoria de impacto de ocupação do solo a parede de tijolo de adobe apresentou impacto $69,4 \%$ maior do que o impacto da parede de tijolo cerâmico. Em relação às coberturas, o uso da laje apresentou impacto maior para 
todas as categorias. O impacto do forro de madeira representou entre $0,7 \%$ e $3,0 \%$ do impacto da laje maciça.

Com isso, o conjunto que obteve o menor impacto, considerando somente os materiais, foi o de paredes de adobe e cobertura de telha cerâmica com forro de madeira.

Figura 7 - Impactos relativos ao valor máximo de cada categoria de impacto para os materiais

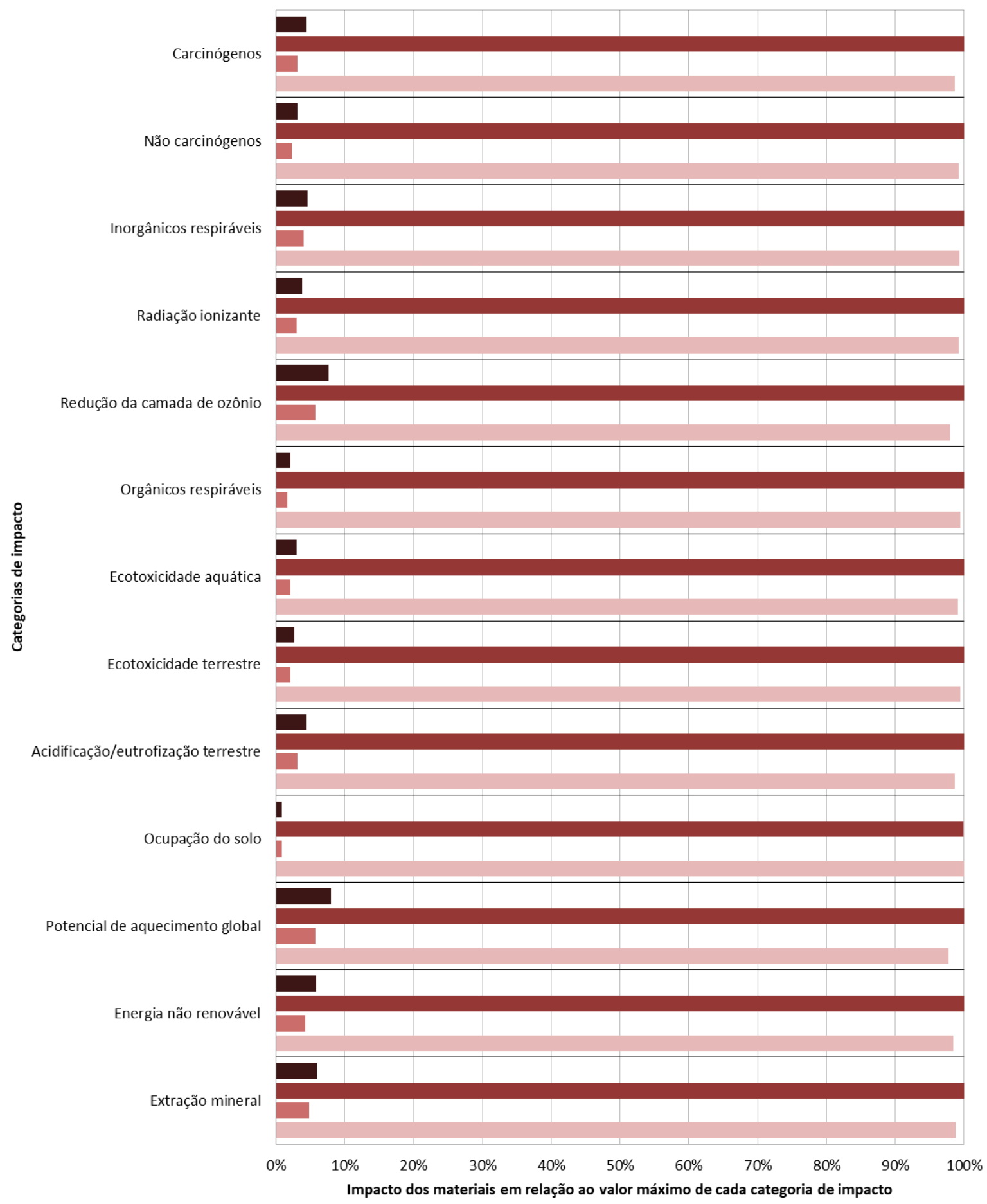

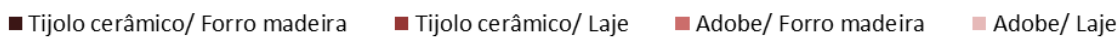


Apesar de aumentar o impacto embutido, conforme apresentado na Figura 7, o uso da laje maciça na cobertura reduziu o consumo energético anual em 5,6\% no caso de paredes de tijolo cerâmico e 3,9\% no caso de paredes de adobe (considerando consumo médio das quatro orientações). Considerando um ciclo de vida de 50 anos e a matriz energética brasileira, o impacto do uso dos materiais e do consumo energético para cada caso é apresentado na Figura 8.

Figura 8 - Impactos relativos ao valor máximo de cada categoria de impacto para todo o ciclo de vida

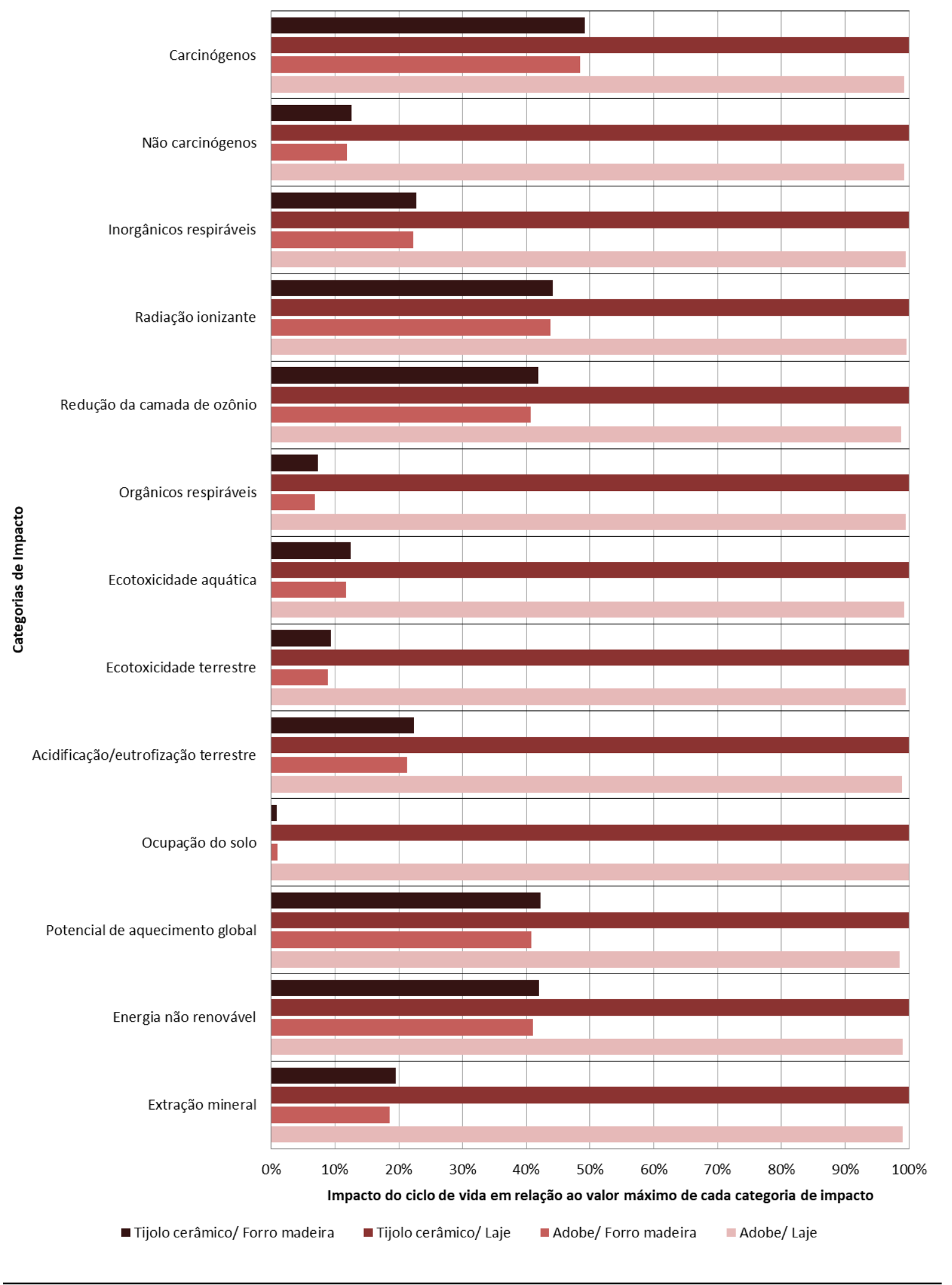

136 Azevedo, L. D. de; Geraldi, M. S.; Ghisi, E. 
Apesar da redução no consumo energético, o uso da laje maciça apresentou aumento significativo do impacto no ciclo de vida. Esse fator pode ser alterado se consideradas outras matrizes energéticas, visto que a matriz brasileira apresenta $42,9 \%$ de fontes renováveis, valor muito diferente da matriz energética global, que tem apenas $1,6 \%$ de fontes renováveis.

Para a maioria das categorias de impacto, o consumo energético durante a operação dos conjuntos com forro de madeira representou mais de $77 \%$ do impacto total. Somente para a categoria de ocupação do solo o percentual foi menor, resultando em $11,5 \%$ para a parede de tijolo cerâmico e 10,9\% para a parede de tijolo de adobe. $\mathrm{O}$ valor máximo de contribuição foi para a categoria de impacto de carcinógenos, para a qual o consumo energético correspondeu a $95,0 \%$ e $96,5 \%$ do impacto total na categoria para as paredes de tijolo cerâmico e tijolo de adobe, respectivamente.

O valor de contribuição no impacto do consumo energético para os conjuntos com a cobertura de laje maciça variou de $0,1 \%$ até $44,7 \%$ entre as categorias. O maior valor ocorreu na categoria de ocupação do solo e o menor na de carcinógenos.

Com exceção da categoria de impacto de ocupação do solo, os conjuntos com parede de tijolo de adobe apresentaram valores de impacto no ciclo de vida inferiores àqueles com parede de tijolo cerâmico. Para as coberturas, mesmo com a redução no consumo energético na fase de operação, os conjuntos com o uso de laje maciça apresentaram valores maiores do que os de forro de madeira.

Considerando todo o ciclo de vida, o conjunto que utiliza parede de tijolos de adobe e cobertura com forro de madeira apresentou os menores valores de impacto em todas as categorias consideradas.

Para confirmar o perfil de impacto dos componentes construtivos considerados, o método ReCiPe foi utilizado considerando o mesmo inventário apresentado anteriormente. A Figura 9 mostra os resultados em percentual e a Tabela 7 os valores brutos.

Das dezoito categorias de impacto consideradas, treze delas apresentaram o mesmo perfil de impacto obtido por meio da aplicação do método IMPACT 2002+. No entanto, para as categorias de depleção estratosférica de ozônio, formação de ozônio (ecossistemas terrestres), eutrofização marinha, eutrofização de água doce e formação de partículas finas os perfis de impacto variaram. Para as quatro primeiras categorias, o conjunto de maior impacto foi o de tijolo cerâmico com forro de madeira, e o de menor impacto foi o de adobe com laje maciça.

Para a categoria de formação de partículas finas, o conjunto de maior impacto foi o de parede de tijolo cerâmico e cobertura de laje maciça, e o menor o de parede de tijolo de adobe e cobertura de forro de madeira.

Apesar de algumas diferenças dos resultados obtidos pelos dois métodos, eles mostraram-se coerentes para a maioria das categorias de impacto. Com isso, o conjunto que apresentou menor impacto ambiental no ciclo de vida para a maioria das categorias foi o de parede de tijolos de adobe e cobertura com forro de madeira. Caso se considerasse apenas o consumo de energia para tomada de decisão, provavelmente, este não seria o conjunto escolhido, pois apresenta consumo $4,1 \%$ maior do que o conjunto de parede de adobe e laje maciça.

\section{Conclusão}

Por meio deste estudo foi possível avaliar o ciclo de vida de diferentes conjuntos de parede e cobertura para compor habitações de interesse social, na cidade de Florianópolis. Entre os sistemas construtivos avaliados, o uso de paredes de tijolo de adobe e cobertura com forro de madeira apresentou tendência a ter menores impactos ambientais.

A aplicação da ACV no setor da construção civil, para o Brasil, ainda está em processo de desenvolvimento e de padronização do método. O desenvolvimento de normas específicas para o setor torna-se indispensável para facilitar a sua aplicação, ampliando os estudos desenvolvidos no país com a aplicação da ACV e o conhecimento acerca do tema. 
Figura 9 - Impactos relativos ao valor máximo de cada categoria de impacto para todo o ciclo de vida por meio do método ReCiPe

\author{
Aquecimento global \\ Depleção estratosférica de ozônio \\ Radiação ionizante \\ Formação de ozônio, Saúde humana \\ Formação de partículas finas
}

Formação de ozônio, ecossistemas terrestres

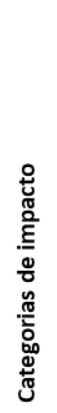

Toxicidade não carcinogênica humana

Uso da terra

Escassez de recursos minerais

Escassez de recursos fósseis

Consumo de água

$$
0 \%
$$

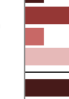

1
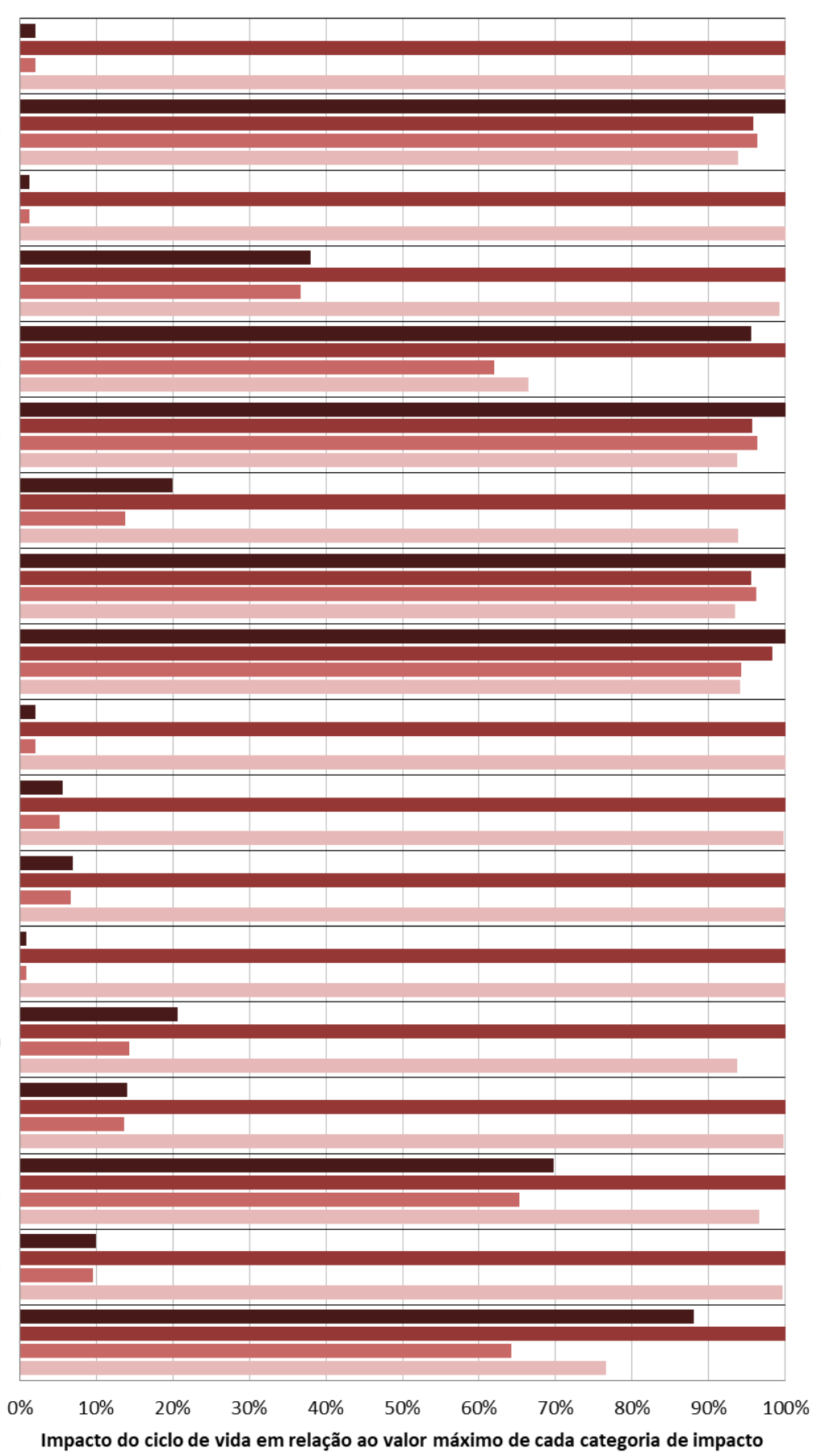

-Tijolo cerâmico/ Laje $\quad$ Adobe/ Forro madeira $\quad$ Adobe/ Laje 
Tabela 7 - Valores de impacto obtidos para todo o ciclo de vida por categoria de impacto conforme o método ReCiPe

\begin{tabular}{|c|c|c|c|c|}
\hline \multirow[b]{2}{*}{ Categoria de impacto } & \multicolumn{4}{|c|}{ Modelo } \\
\hline & $\begin{array}{l}\text { Tijolo cerâmico/ } \\
\text { Forro madeira }\end{array}$ & $\begin{array}{l}\text { Tijolo } \\
\text { cerâmico/ Laje }\end{array}$ & $\begin{array}{c}\text { Adobe/ } \\
\text { Forro } \\
\text { madeira }\end{array}$ & $\begin{array}{l}\text { Adobe/ } \\
\text { Laje }\end{array}$ \\
\hline Aquecimento global (kg CO $\left.\mathrm{CO}_{2} \mathrm{eq}\right)$ & 1730,78 & 82086,43 & 1717,66 & 82079,39 \\
\hline $\begin{array}{l}\text { Depleção estratosférica de ozônio (kg } \\
\text { CFC }_{11} \text { eq) }\end{array}$ & 6,28 & 6,02 & 6,05 & 5,89 \\
\hline Radiação ionizante (kBq Co-60 eq) & 73,28 & 5749,62 & 73,24 & 5749,60 \\
\hline $\begin{array}{l}\text { Formação de ozônio, Saúde humana (kg } \\
\text { NOx eq) }\end{array}$ & 266,08 & 699,36 & 256,61 & 694,27 \\
\hline Formação de partículas finas (kg PM2.5 eq) & 5549,81 & 5807,81 & 3599,69 & 3859,42 \\
\hline $\begin{array}{l}\text { Formação de ozônio, ecossistemas } \\
\text { terrestres (kg NOx eq) }\end{array}$ & 56686,91 & 54252,63 & 54623,00 & 53144,25 \\
\hline Acidificação terrestre $\left(\mathrm{kg} \mathrm{SO}_{2}\right.$ eq) & 83,43 & 418,57 & 57,84 & 392,98 \\
\hline Eutrofização de água doce (kg P eq) & 4918,67 & 4698,51 & 4734,29 & 4596,82 \\
\hline Eutrofização marinha (kg N eq) & 87,15 & 85,74 & 82,09 & 82,07 \\
\hline Ecotoxicidade terrestre (kg 1,4-DCB) & 7529,25 & 359590,42 & 7520,18 & 359582,8 \\
\hline Ecotoxicidade em água doce (kg 1,4-DCB) & 131,97 & 2345,41 & 124,04 & 2338,89 \\
\hline Ecotoxicidade marinha (kg 1,4-DCB) & 236,57 & 3425,99 & 229,72 & 3422,19 \\
\hline $\begin{array}{l}\text { Toxicidade cancerígena humana (kg 1,4- } \\
\text { DCB) }\end{array}$ & 69,53 & 8002,00 & 68,94 & 8001,65 \\
\hline $\begin{array}{l}\text { Toxicidade não carcinogênica humana (kg } \\
1,4-\mathrm{DCB})\end{array}$ & 19201,21 & 93274,76 & 13292,20 & 87365,76 \\
\hline Uso da terra $\left(\mathrm{m}^{2} \mathrm{a}\right.$ crop eq $)$ & 81816,58 & 580065,31 & 78945,20 & 578509,3 \\
\hline Escassez de recursos minerais ( $\mathrm{kg} \mathrm{Cu} \mathrm{eq)}$ & 1429,43 & 2049,54 & 1337,94 & 1979,97 \\
\hline Escassez de recursos fósseis (kg óleo eq) & 2340,10 & 23366,54 & 2226,07 & 23281,33 \\
\hline Consumo de água $\left(\mathrm{m}^{3}\right)$ & 3692,13 & 4190,28 & 2690,45 & 3208,68 \\
\hline
\end{tabular}

Reconhece-se como uma limitação do trabalho a falta de acesso e inexistência de alguns materiais para compor a base de dados utilizada para obtenção do impacto ambiental dos materiais no Brasil. Utilizar uma base de dados estrangeira pode apresentar padrões distintos da realidade local. Além disso, apesar de ser uma excelente ferramenta para levantamento do consumo energético, a simulação desenvolvida pode apresentar resultados distintos quando modelada por diferentes pesquisadores. Como o algoritmo padrão do programa de simulação computacional utilizado não abrange as trocas de umidade, apesar de ser a principal característica da parede de adobe para o conforto térmico, tais trocas não foram consideradas nas simulações computacionais.

O uso de dois métodos de AICV apresentou a possibilidade de resultados diversos conforme as decisões tomadas ao longo do escopo do trabalho. Como sugestão para trabalhos futuros, indica-se o desenvolvimento de uma análise de sensibilidade com a alteração de algumas variáveis como a consideração da fase de manutenção da edificação, alteração no tempo de vida útil, consideração de diferentes distâncias de transporte dos materiais, diferentes perfis de usuários, entre outros fatores.

\section{Referências}

ASADOLLAHFARDI, G.; ASADI, M.; KARIMI, S. Life-cycle assessment of construction in a developing country. Environmental Quality Management, v. 24, n. 4, p. 11-21, jun. 2015.

ASSOCIAÇÃO BRASILEIRA DE NORMAS TÉCNICAS. NBR ISO 14040:2009: gestão ambiental: avaliação do ciclo de vida: princípios e estrutura. Rio de Janeiro, 2014.

BRASIL. Ministério de Minas e Energia. Empresa de Pesquisa Energética. Balanço Energético Nacional. Rio de Janeiro: Epe, 2017.

BUILDING RESEARCH ESTABLISHMENT. Global methodology for the environmental assessment of buildings using EN 15978:2011. Reino Unido: BRE Global Ltd, 2018. 
BUYLE, M.; BRAET, J.; AUDENAERT, A. Life cycle assessment in the construction sector: a review. Renewable and Sustainable Energy Reviews, v. 26, p. 379-388, out. 2013.

CALDAS, L. R. et al. Sustentabilidade na Construção Civil. Sustentabilidade em Debate, v. 7, n. 2, p. 238256, nov. 2016.

CALDAS, L. R.; LIRA, J. S. de M. M.; SPOSTO, R. M. Avaliação do Ciclo de Vida de habitações de alvenaria estrutural de blocos cerâmicos e painéis pré-moldados de concreto considerando diferentes zonas bioclimáticas. Revista Latino-americana em Avaliação do Ciclo e Vida, Brasília, v. 1, n. 1, p.138-167, dez. 2017.

CHRISTOFOROU, E. et al. Cradle to site Life Cycle Assessment (LCA) of adobe bricks. Journal of Cleaner Production, v. 112, p. 443-452, jan. 2016.

CURRAN, M. A. Life cycle assessment: a review of the methodology and its application to sustainability. Current Opinion in Chemical Engineering, Cincinnati, v. 2, n. 3, p.273-277, ago. 2013.

GHISI, E. et al. Uso racional de água e eficiência energética em habitações de interesse social: volume 1: hábitos e indicadores de consumo de água e energia. Florianópolis: Laboratório de Eficiência Energética em Edificações, 2015.

HARISH, V. S. K. V.; KUMAR, A. A review on modeling and simulation of building energy systems. Renewable and Sustainable Energy Reviews, v. 56, p. 1272-1292, abr. 2016.

HUMBERT, S. et al. IMPACT 2002+: user guide. Quantis, 2012.

INTERNATIONAL ENERGY AGENCY. World Energy Outlook 2019. 2019. Disponível em: https://www.eia.gov/outlooks/ieo/pdf/ieo2019.pdf/. Acesso em: 03 mar. 2020.

KYLILI, A.; ILIC, M.; FOKAIDES, P. A. Whole-building Life Cycle Assessment (LCA) of a passive house of the sub-tropical climatic zone. Resources, Conservation and Recycling, v. 116, p.169-177, jan. 2017.

LOPES, T. do P. Desempenho térmico de habitações de interesse social com diferentes sistemas construtivos em Santa Catarina. Florianópolis, 2010. 128 f. Dissertação (Mestrado em Engenharia Civil) Curso de Engenharia Civil, Universidade Federal de Santa Catarina, Florianópolis, 2010.

MENESES, T. A. da F. Estudo do comportamento térmico de construções em alvenaria de adobe. Aveiro, 2010. 138 f. Tese (Doutorado em Engenharia Civil) - Programa de Pós-Graduação em Engenharia Civil, Universidade de Aveiro, Aveiro, 2010.

MONTES, M. A. T. Abordagem Integrada no Ciclo de Vida de Habitações de Interesse Social considerando mudanças climáticas. Florianópolis, 2016. 573 f. Tese (Doutorado em Engenharia Civil) Programa de Pós-Graduação em Engenharia Civil, Universidade Federal de Santa Catarina, Florianópolis, 2016.

NATIONAL INSTITUTE FOR PUBLIC HEALTH AND THE ENVIRONMENT. Ministry Of Health.

ReCiPe 2016 v1.1: a harmonized life cycle impact assessment method at midpoint and endpoint level: report I: characterization. Bilthoven: Rivm, 2017.

PAULSEN, J. S.; SPOSTO, R. M. A life cycle energy analysis of social housing in Brazil: case study for the program "MY HOUSE MY LIFE”. Energy and Buildings, v. 57, p. 95-102, fev. 2013.

PROGRAMAS DE EMPLEO Y JUVENTUD. Proyecto de Energía Solar Sto. Tórnas. Casas Solares 1: Manual de Construcción. Energía Solar en los Andes. Peru: Asociación Religiosa Programas de Empleo y Juventud Prelatura de Sicuani, 2009.

RAMESH, T.; PRAKASH, R.; SHUKLA, K. K. Life cycle energy analysis of buildings: an overview. Energy and Buildings, v. 42, n. 10, p. 1592-1600, out. 2010.

RASHID, A. F. A.; YUSOFF, S. A review of life cycle assessment method for building industry. Renewable and Sustainable Energy Reviews, v. 45, p. 244-248, maio 2015.

SOUZA, D. M. de et al. Comparative life cycle assessment of ceramic brick, concrete brick and cast-inplace reinforced concrete exterior walls. Journal of Cleaner Production, v. 137, p. 70-82, nov. 2016.

TABELAS de Composição de Preços para Orçamentos. 13. ed. São Paulo: Pini, 2010.

TRIANA, M. A.; LAMBERTS, R.; SASSI, P. Characterisation of representative building typologies for social housing projects in Brazil and its energy performance. Energy Policy, v. 87, p. 524-541, dez. 2015. 
VAN OOTEGHEM, K.; XU, L. The life-cycle assessment of a single-storey retail building in Canada. Building and Environment, v. 49, p. 212-226, mar. 2012.

WANG, H.; ZHAI, Z. Advances in building simulation and computational techniques: a review between 1987 and 2014. Energy and Buildings, v. 128, p. 319-335, set. 2016.

WEBER, F. S. et al. Elaboração de uma biblioteca de componentes construtivos brasileiros para o uso no programa EnergyPlus. Florianópolis: LABEEE, 2017.

Leticia Dalpaz de Azevedo

Departamento de Engenharia Civil | Universidade Federal de Santa Catarina | Campus Universitário João David Ferreira Lima, Bloco B | Florianópolis - SC -Brasil | CEP 88037-000 | Tel.: (48) 3721-2390 | E-mail: ledalpaz@hotmail.com

\section{Matheus Soares Geraldi}

Departamento de Engenharia Civil | Universidade Federal de Santa Catarina | E-mail: matheus.s.geraldi@gmail.com

\section{Enedir Ghisi}

Departamento de Engenharia Civil | Universidade Federal de Santa Catarina | Tel.: (48) 3721-2115 | E-mail: enedir.ghisi@ufsc.br

\section{Ambiente Construído}

Revista da Associação Nacional de Tecnologia do Ambiente Construído

Av. Osvaldo Aranha, $99-3^{\circ}$ andar, Centro

Porto Alegre - RS - Brasil CEP $90035-190$

Telefone: +55 (51) 3308-4084

Fax: +55 (51) 3308-4054

www.seer.ufrgs.br/ambienteconstruido

E-mail: ambienteconstruido@ufrgs.br

This is an open-access article distributed under the terms of the Creative Commons Attribution License. 